\title{
TURÁN TYPE INEQUALITIES FOR GENERALIZED MITTAG-LEFFLER FUNCTION
}

\author{
LI YIN AND LI-GUO HUANG
}

Abstract. In the present paper, we introduce a generalization of Mittag-Leffler function by considering the $p$-gamma function. Some Turán type inequalities for generalized Mittag-Leffler function were obtained.

Mathematics subject classification (2010): 33E12, $26 \mathrm{D} 07$. tion.

Keywords and phrases: Turán type inequalities; generalized Mittag-Leffler function; $p$-gamma func-

\section{REFERENCES}

[1] K. Dethelm, The analysis of fractional differential equations: an application-oriented exposition using differential operatiors of Caputo type, Lecture notes in mathematics, Heidelberg and New York: Springer-Verlag, 2010.

[2] A. A. Kilbas, H. M. Srivastava And J. J. Trujillo, Theory and applications of fractional differential equations. Moscow: Nauka, 1966.

[3] M. M. DZHERBASHYAN, Integral transform representations of functions in the complex domain. Ansterdam: Elsevier, 2006.

[4] R. Gorenflo, A. A. Kilbas, F. Mainardi and S. V. Rogosin, Mittag-Leffler funtions, related topics and applications. New York: Springer, 2014.

[5] F. W. J. Olver, D. W. LOZIER, R. F. Boisvert AND C. W. Clark, NIST handbook of mathematical functions. Cambridge: Cambridge University Press, 2010.

[6] K. Mehrez And S. M. Sitnik, Turán type inequalities for Mittag-Leffler functions. Available online at http://arxiv.1603.08504v1.

[7] K. MehreZ And S. M. Sitnik, Turán type inequalities for classical and generalized Mittag-Leffler functions. Available online at http://arxiv.1603.08504v2.

[8] K. MehreZ AND S. M. Sitnik, Proofs of some conjectures on monotonicity of ratios of Kummer, Gauss and generalized hypergeometric functions. Available online at http://arxiv.org/abs/1411.6120.

[9] S. Ponnus Amy AND M. VuORInen, Asympotic expansion and inequalities for hypergeometric functions. Mathematika 44, (1997), 278-301. 